\title{
A nationwide survey of pharmacy students' knowledge and perceptions regarding medical cannabis
}

\author{
Karen E. Moeller*, J. Michael McGuire, Brittany L. Melton
}

\section{A R T I C L E I N F O}

\section{Article history:}

Received 31 May 2019

Accepted 22 August 2019

Available online 1 October 2019

\begin{abstract}
A B S T R A C T
Objective: The primary objective of this study was to compare knowledge and perceptions of medical cannabis (MC) between pharmacy students who attended schools where MC was legal and illegal.

Design: A nationwide anonymous survey regarding MC was distributed to pharmacy students. The survey consisted of the following sections: (1) demographics and personal factors, (2) knowledge assessment of indications and adverse effects of MC, and (3) perceptions assessment.

Setting and participants: Equal numbers of pharmacy schools were selected and sent surveys based on geographical regions, private versus public universities, and the state's legal status of MC for first through fourth-year pharmacy students to complete.

Outcome measures: Student knowledge of MC indications and adverse effects were treated as quizzes. Median percentage correct and whether students passed the quizzes ( $\geq 70 \%$ ) were evaluated based on the state's legal status. Students' perceptions were similarly compared. Results: A total of 629 students accessed the survey. Most students who completed the survey attended pharmacy schools where MC was illegal (55\%), were female (68\%), and had personally tried cannabis (53\%). Overall, $91 \%$ of students believed that MC should be legalized nationally. A low number of students correctly identify approved indications with $14.8 \%$ of students in states with MC legalization scoring greater than $70 \%$ compared with $15.9 \%$ of students in states without MC legalization $(P=0.748)$. Similar findings were seen in the side effects quiz with only $6.1 \%$ of students in states with legal MC scoring greater than $70 \%$ compared with $7.4 \%$ of students where MC is illegal $(P=0.569)$ There were minimal differences in students' perceptions of MC based on the states' legal status.

Conclusion: Our study continues to highlight that pharmacy students lack knowledge and preparation to counsel and educate on MC. With increasing state legalizations, pharmacy schools need to address this knowledge gap to ensure optimal patient care.
\end{abstract}

() 2020 American Pharmacists Association ${ }^{\circledR}$. Published by Elsevier Inc. All rights reserved.
Cannabis is the most commonly abused illicit substance worldwide. ${ }^{1}$ Since California first legalized medical cannabis (MC) in 1996, there has been a dramatic shift in the landscape of MC in terms of availability as well as public opinion. ${ }^{2}$ As of 2019, 33 states and the District of Columbia have MC laws resulting in more than half of the U.S. population living in a

Disclosures: Dr. McGuire has received honorarium or consultant fees from Sunovion Pharmaceuticals, Alkermes Inc, and Otsuka America Pharmaceuticals Inc. Dr. McGuire also holds stock in Bristol-Myers Squibb Inc.

Previous presentation: Poster presentation at AACP 2019 Annual Meeting.

* Correspondence: Karen E. Moeller, PharmD, BCPP, Clinical Professor, Pharmacy Practice, University of Kansas, School of Pharmacy, 2010 Becker Dr, Room 2001, Lawrence, KS 66047.

E-mail address: kmoeller@kumc.edu (K.E. Moeller). state with MC legally available. ${ }^{3}$ Public opinion has likewise dramatically changed with a 2016 survey finding that $81 \%$ of respondents favor legalization of cannabis for medical use. ${ }^{1}$ Although public opinion supports legalization for medical use, there remains controversy regarding the safety and efficacy of MC, and conflicts between state and federal law with cannabis remaining a Schedule I controlled substance. ${ }^{1}$

Cannabis is a complex compound containing hundreds of cannabinoids, flavonoids, and terpenoids. ${ }^{4}$ The cannabinoids of greatest interest are delta-9-tetrahydrocannabinol (THC), the primary psychoactive component, and cannabidiol (CBD). Reports in the media and the Internet abound on the potential benefits of THC and CBD; however, the evidence is conflicting or lacking regarding their safety or efficacy. The National Academies of Science published a comprehensive review of 


\section{Key Points}

\section{Background:}

- Over half of the U.S. population lives in an area where medical cannabis (MC) is legal.

- Pharmacists are now playing an increasing role in providing drug information on MC.

- Previous studies of pharmacy students conducted in single states showed pharmacy students lack knowledge of MC.

\section{Findings:}

- Pharmacy students continue to lack knowledge on indications and adverse effects of MC. Minimal differences in knowledge and perceptions were exhibited based on state cannabis laws where pharmacy students attended school.

- Over $80 \%$ of pharmacy students think MC is safe, which mirrors public perceptions.

- Most pharmacy students support MC legalization, and nearly all students feel instruction on MC should be in pharmacy school curriculums.

the efficacy and safety of cannabis, which found conclusive or substantial evidence that cannabis or cannabinoids are effective for the treatment of chronic pain, chemotherapy-induced nausea and vomiting, and spasticity in multiple sclerosis. ${ }^{5}$ There are 2 Food and Drug Administration-approved prescription medication formulations of THC (dronabinol and nabilone) and 1 approved formulation of CBD (cannabidiol). ${ }^{6-8}$ Dronabinol and nabilone are both indicated for chemotherapy-induced emesis in patients who have failed other anti-emetic agents, whereas dronabinol is also approved for anorexia in patients with acquired immunodeficiency syndrome. ${ }^{7,8}$ The cannabidiol prescription formulation is approved for the treatment of seizures associated with Lennox-Gastaut syndrome or Dravet syndrome. ${ }^{6}$

Pharmacists are considered the most accessible health care professionals in the United States, with 90\% of Americans living within 5 miles of a community pharmacy. ${ }^{9}$ With increasing legalization of both recreational and MC, patients, consumers, and health- care professionals are likely to rely on pharmacists for knowledge on cannabis's efficacy, safety, dosing, and drug interactions. Surveys of pharmacy students have shown more than half of pharmacy students support MC legalization, with a recent survey showing an $85 \%$ acceptance rates in 2018 at a private pharmacy school in the Midwest. ${ }^{10,11}$ Some states have moved to include pharmacists in the dispensing of MC in some capacity. ${ }^{2}$ Connecticut, Minnesota, New York, and Pennsylvania require a pharmacist or a health care professional, depending on the state, to be onsite at MC dispensaries, whereas Arkansas requires dispensaries to appoint a pharmacist consultant. ${ }^{12-14}$ In Louisiana, the Board of Pharmacy is required to establish standards for packaging, labeling, and dispensing of MC at Marijuana Pharmacies. ${ }^{15}$ In addition, CBD supplements are being sold at pharmacies nationwide. ${ }^{16}$ Given the accessibility of pharmacists and the increasing availability of both medical and recreational cannabis, pharmacists should understand the impact that cannabis can have on an individual's illnesses and concomitant drug therapy. Pharmacists are being asked about cannabis, and $\mathrm{CBD}$, even if their state does not require involvement in its dispensing. Furthermore, pharmacists should be gathering information about the use of cannabis to identify any impact on the patient's pharmacotherapy regimen consistent with the American Pharmacist Association (APhA) position statement. ${ }^{17}$

The American Society of Health System Pharmacist (ASHP) and APhA have developed position statements regarding MC. ${ }^{17,18}$ Both organizations support the education of pharmacists to respond to patient and clinician questions. However, surveys of pharmacists and pharmacy students have shown that more training and education is necessary to answer clinical questions on MC. ${ }^{10,11,19-21}$

Three published studies have assessed pharmacy student knowledge about MC. ${ }^{10,11,19}$ Two studies were conducted at Midwestern pharmacy schools where MC was illegal, in 2011 and 2017. ${ }^{10,11}$ Both studies surveyed first through third year pharmacy students and found that most students were not able to correctly identify conditions for which MC is generally permitted. Berlekamp et al. also surveyed pharmacy students' knowledge and attitudes about cannabis but in a state where MC became legally available in 2017. ${ }^{19}$ In their survey of pharmacy students, the authors also found low knowledge about MC regarding indications, adverse effects, and cytochrome P450 interactions. All authors concluded that there was a knowledge gap for pharmacy students regarding MC at their institutions.

\section{Objectives}

In the present study, the authors sought to update the results of the previous Moeller and Woods study conducted in 2011 by expanding the survey to include pharmacy schools nationally. In addition, the authors sought to compare knowledge and perceptions of pharmacy students in schools that are located in states with and without MC laws.

\section{Methods}

An anonymous online survey (Qualtrics, Provo, UT) regarding pharmacy students' perceptions and knowledge of MC was distributed to select schools of pharmacy across the United States in early fall 2018. Equal numbers of schools were selected based on geographical regions (Southeast, Northeast, Midwest, Southwest, West), private versus public universities, and the state's legal status of MC, to provide balanced representation. Pharmacy schools' deans at 44 institutions were first sent an e-mail asking them to distribute the survey among their first through fourth-year pharmacy students. Reminder e-mails were sent mid-fall semester, and the survey closed at the end of the fall semester. At the time of survey distribution, 31 states and DC had legalized MC, and 9 states and DC had approved recreational cannabis. The survey was voluntary and was approved by the Human Subjects Committees at The University of Kansas and Belmont University.

The survey was adopted and updated from the lead author's survey distributed to pharmacy students at a Midwest 
public university in 2011 where MC was illegal. At the time of the original survey development, only 14 states had approved MC. The previous survey has been adapted for use and cited in other health care professional surveys. ${ }^{10,11,22}$

The current survey consisted of 3 sections: (1) demographics and personal factors, (2) knowledge assessment of indications and adverse effects of MC, and (3) perceptions assessment (5-point Likert scale questions). The survey instrument is in Appendix 1, available on JAPhA.org as supplemental content.

Demographic information collected included age, gender, year in pharmacy school and pharmacy school information (public vs. private, and state). Personal factors addressed included family and personal history of substance abuse, history of cannabis use, and personal connection to someone using MC. Students were also asked if they had received any formal education on MC as part of the required curriculum.

The second section of the survey assessed students' knowledge of qualifying conditions and adverse effects regarding MC. Students were provided with a list of 19 conditions and were asked the following question "States vary regarding qualified conditions for medical use of marijuana. From the list below, please select which of the following are common uses for medical marijuana." Four of the conditions were considered false or incorrect (hypertension, depression, schizophrenia, and sleep apnea). The correct uses were selected from a list of qualifying conditions in legal states at time of survey development. Of the 15 correct answers, the majority of qualifying conditions were approved in more than three-fourths of the states. All indications were approved in at least 4 or more states. Students were next asked to select potential adverse effects from a list of 21 symptoms with 5 incorrect answers (water retention, muscle aches, constipation, hypoglycemia, and increased bleeding).

The last section of the survey assessed student's perceptions and confidence in answering questions regarding medical and recreational cannabis. Students were presented with 31 Likert scale questions $(1=$ strongly disagree and $5=$ strongly agree). For analysis, responses were grouped into agree/strongly agree and all other responses to produce a dichotomous variable.

Differences between students attending pharmacy schools in states with legalized MC and those attending schools in states without MC were compared. Select student demographics, training regarding cannabis, and perceptions about cannabis were compared using chi-square. Student knowledge of MC indications and adverse effects were treated as quizzes for analysis, and both the percentage of questions correct and whether or not students passed the quizzes ( $\geq 70 \%$ ) were also evaluated. Median percentage correct was compared using Mann-Whitney $U$ test, and number of students passing was assessed using chi-square. A subanalysis was run comparing quiz results between students who reported having an in-depth discussion regarding MC in pharmacy school and those who did not, to see if in-depth discussions improved knowledge. In addition, the authors compared quiz results of first- and second-year professional students (P1/P2) to third- and fourth-year professional students (P3/P4). Statistical analyses were performed using SPSS 25 (IBM, Armonk, NY) with an a priori alpha at 0.05 .

\section{Results}

Of the 44 schools that were contacted, three schools replied they would not distribute the survey based on school policy. Students from 10 states filled out the survey. Seven states (Florida, Illinois, Massachusetts, New Mexico, New York, Ohio, and West Virginia) had MC laws, and 3 states (Idaho, Kansas, and Tennessee) were without MC laws. Because the survey was distributed to multiple schools in states that responded (3 in Florida, 2 in Illinois, 2 in Idaho, 2 in Massachusetts, 2 in Ohio, and 2 in Tennessee), the authors were unable to determine the number of schools that responded. Based on the number of schools that were sent the survey and the states that responded, a maximum of 17 schools of pharmacy may have been surveyed. However, in states where multiple schools were surveyed, the authors were unable to determine if more than 1 school filled out the survey, so a minimum of 10 schools may have been surveyed.

A total of 629 students accessed the survey, and of those, $505(80.3 \%)$ responded to most or all of the items. Demographics for students enrolled in pharmacy schools in states with MC and those in states without MC are shown in Table 1 and were not significantly different. Only 14.9\% (29 of 195 and 46 of 308 students, respectively) of students in both groups reported having an in-depth discussion of MC as part of their core curriculum. Furthermore, 94.9\% (186/196) of the students in the MC states, and $96.1 \%$ (298/310) of the students

Table 1

Demographics

\begin{tabular}{|c|c|c|c|c|}
\hline Demographics & Total & School in states with MC & School in states without MC & $P$ value \\
\hline Age median (IQR) & $23(22-25)$ & $23(22-26)$ & $23(22-25)$ & \\
\hline Gender, n (\%) & $(\mathrm{n}=505)$ & $(\mathrm{n}=196)$ & $(\mathrm{n}=309)$ & \\
\hline Female & $345(68.3)$ & 135 (68.9) & $210(68)$ & \\
\hline Male & $160(31.7)$ & $61(31.1)$ & $99(32)$ & \\
\hline Year in pharmacy school, $\mathrm{n}(\%)$ & $(n=505)$ & $(\mathrm{n}=196)$ & $(\mathrm{n}=309)$ & \\
\hline P1 & $112(22.2)$ & $53(27)$ & $59(19.1)$ & \\
\hline P2 & $118(23.4)$ & $51(26)$ & $67(21.7)$ & \\
\hline P3 & $133(26.3)$ & $43(21.9)$ & $90(29.1)$ & \\
\hline P4 & $142(28.1)$ & $49(25)$ & $93(30.1)$ & \\
\hline Family history of substance abuse, $\mathrm{n}(\%)$ & $180(30.3)(\mathrm{n}=595)$ & $68(28.2)(n=241)$ & $112(31.6)(\mathrm{n}=354)$ & 0.372 \\
\hline Personal history of substance abuse, $\mathrm{n}(\%)$ & $26(4.4)(n=595)$ & $12(5)(n=241)$ & $14(4)(n=354)$ & 0.548 \\
\hline Knows someone who used marijuana, n (\%) & $271(53.7)(n=505)$ & $113(57.9)(\mathrm{n}=195)$ & $158(51)(\mathrm{n}=310)$ & 0.126 \\
\hline Personally used marijuana, n (\%) & $264(52.7)(\mathrm{n}=501)$ & $102(52.6)(\mathrm{n}=194)$ & $162(52.8)(\mathrm{n}=307)$ & 0.967 \\
\hline Received in-depth discussion of $\mathrm{MC}, \mathrm{n}(\%)$ & $75(14.9)(\mathrm{n}=503)$ & $29(14.9)(n=195)$ & $46(14.9)(n=308)$ & 0.985 \\
\hline
\end{tabular}

Abbreviations used: IQR, interquartile range; MC, medical cannabis. 


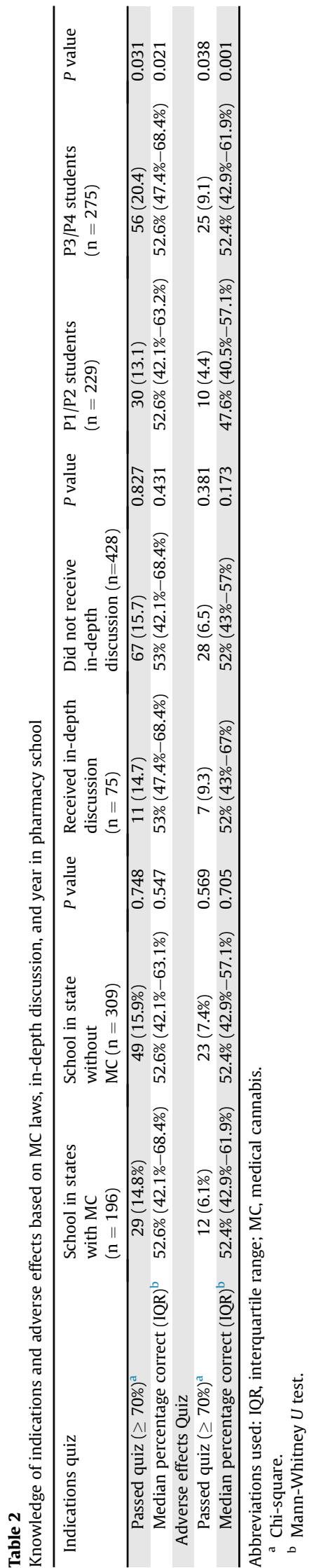

in the non-MC states thought faculty should include information about $\mathrm{MC}$ in their classes $(P=0.508)$.

Student knowledge of indications and adverse effects are shown in Table 2. Students in schools whose state has MC legalization did not have a higher percentage of students scoring greater than $70 \%$ correct on indications compared with students in states without MC (14.8\% vs. $15.9 ; P=0.748$, respectively). Further, students in MC states did not score greater than $70 \%$ more than students in states without MC when looking at the side effects (6.1\% vs $7.4 \% ; P=0.569$, respectively). A subanalysis of those who received in-depth discussions versus those who did not is shown in Table 2, and no differences were seen between groups. However, when we looked at year in pharmacy school, the P3/P4 students compared with P1/P2 students were more likely to pass both the indications ( $20.4 \%$ vs. $13.1 \% ; P=0.031$, respectively) and adverse effect quizzes (9.1\% vs. $4.4 \% ; P=0.038$, respectively).

Perceptions about cannabis (medical, recreational, and confidence in providing drug information on $\mathrm{MC}$ ) are presented in Table 3. Students in states with MC laws were statistically more likely to think MC was safe in pregnancy $(P=$ $0.008)$, has fewer negative health effects than prescription medications $(P=0.01)$, and less likely to impair one's ability to drive $(P=0.032)$.

\section{Discussion}

To the authors' knowledge, this is the first national study to assess differences in knowledge and perceptions of MC of pharmacy students studying in states where MC is legal or illegal. Overall, the study found minimal differences in knowledge and perceptions of pharmacy students regardless of state MC laws. Moreover, this study continues to show that pharmacy students lack knowledge of MC.

Over $90 \%$ of all pharmacy students surveyed favored MC legalization and nearly three-fourths of students felt pharmacists should be involved in the dispensing process of MC. This high rate of students favoring MC legalization is consistent with a 2017 survey of pharmacy students in Iowa (illegal MC state). ${ }^{10}$ However, it is significantly higher than a 2011 study in which only $59 \%$ favored legalization. ${ }^{11}$

Despite the strong support for pharmacist involvement, less than half of the students surveyed, irrespective of their state cannabis laws, felt knowledgeable concerning efficacy, drug interactions, and providing drug information on MC. This is also evident in the knowledge section of the current survey where the median percent correct score in both the approved indications and adverse effect sections were less than $60 \%$, indicating a failing score for most students. Regarding passing scores, only about $15 \%$ of the students in states with legalized MC scored higher than 70\% for indications compared with about $16 \%$ for students who studied in states where MC was illegal $(P=0.748)$. Students in states with legalized MC were also no more likely to score a passing grade on the adverse effects quiz (6.1\%) compared with students in states with illegal MC (7.4\%; $P=0.569)$. Our results are consistent with Berlekamp et al. study from Ohio, a legal MC state, which found pharmacy students' correct responses ranged between $50 \%$ to $60 \%$ for all knowledge questions. $^{19}$ 
Table 3

Attitudes toward cannabis (agree or strongly agree)

\begin{tabular}{|c|c|c|c|}
\hline Perception questions regarding cannabis & $\begin{array}{l}\text { School in state } \\
\text { with MC, } \mathrm{n}(\%)\end{array}$ & $\begin{array}{l}\text { School in state } \\
\text { without MC, } \mathrm{n}(\%)\end{array}$ & $P$ value \\
\hline In my opinion, marijuana should be legalized for medicinal uses. & $176(89.8)$ & $279(90.3)$ & 0.856 \\
\hline $\begin{array}{l}\text { In my opinion, all clinicians with prescribing rights (e.g., advanced nurse practitioners, } \\
\text { physician assistants) should be able to prescribe MMJ. }\end{array}$ & $106(54.1)$ & $149(48.2)$ & 0.199 \\
\hline In my opinion, I feel pharmacists should be involved in the dispensing process for MMJ. & $144(73.8)$ & $223(72.2)$ & 0.680 \\
\hline I feel that marijuana is safe when used responsibly for medical use. & $158(80.6)$ & $258(83.5)$ & 0.407 \\
\hline I feel MMJ should be available for use in children. & $83(42.3)$ & $117(38.2)$ & 0.359 \\
\hline I feel MMJ is safe to use in pregnancy and lactation. & $20(10.3)$ & $13(4.2)$ & $0.008^{\mathrm{a}}$ \\
\hline I feel that marijuana can be detrimental to one's health for medical use. & $40(20.4)$ & $61(19.7)$ & 0.855 \\
\hline I feel that MMJ is often abused. & $88(44.9)$ & $147(47.6)$ & 0.557 \\
\hline I feel that legalizing MMJ would cause crimes rates to increase. & $14(7.2)$ & $20(6.5)$ & 0.758 \\
\hline I feel that legalizing MMJ would cause more people to use marijuana in non-medical ways. & $96(49)$ & $160(51.8)$ & 0.54 \\
\hline I consider myself knowledgeable on the subject of MMJ. & $60(30.6)$ & $85(27.5)$ & 0.452 \\
\hline I understand the difference between delta-9 tetrahydrocannabinol (THC) and cannabidiol (CBD). & $149(76)$ & $242(78.3)$ & 0.547 \\
\hline I feel comfortable answering questions from my patients about the efficacy of MMJ. & $62(31.6)$ & $91(29.5)$ & 0.619 \\
\hline I feel comfortable answering questions from my patients about drug interactions with MMJ. & $28(14.3)$ & $40(12.9)$ & 0.667 \\
\hline I feel that MMJ is safe to use with prescription medications. & $47(24)$ & $92(29.8)$ & 0.155 \\
\hline I feel that MMJ is safe to use with non-prescription medications. & $54(27.6)$ & $88(28.5)$ & 0.821 \\
\hline I feel that MMJ has been adequately studied by scientists. & $38(19.4)$ & $55(17.8)$ & 0.654 \\
\hline I feel that the majority of people who support the legalization of MMJ are drug abusers. & $15(7.7)$ & $24(7.8)$ & 0.955 \\
\hline $\begin{array}{l}\text { If I had to make a decision today about legalization of MM, I would be in } \\
\text { favor of doctor prescribed MMJ. }\end{array}$ & $166(84.7)$ & $270(87.7)$ & 0.342 \\
\hline I feel that our government has adequate resources to regulate the use of MMJ. & $123(62.8)$ & $176(57.1)$ & 0.211 \\
\hline In my opinion, marijuana should be legalized for the general population. & $122(62.2)$ & $189(61.4)$ & 0.843 \\
\hline I feel that marijuana is a gateway drug. & $49(25.1)$ & $71(23)$ & 0.581 \\
\hline I feel that marijuana is safe when used responsibly for recreational use. & $117(59.7)$ & $192(62.5)$ & 0.522 \\
\hline I feel that recreational use of marijuana can be detrimental to one's health. & $81(41.3)$ & $131(42.5)$ & 0.789 \\
\hline I feel that legalizing marijuana for any use would cause crime rates to increase. & $15(7.7)$ & $32(10.4)$ & 0.308 \\
\hline I feel marijuana has fewer negative health effects than alcohol. & $136(69.4)$ & $226(73.1)$ & 0.362 \\
\hline I feel users can become addicted to marijuana. & $101(51.5)$ & $175(56.6)$ & 0.262 \\
\hline I feel marijuana has fewer negative health effects than tobacco. & $133(68.2)$ & $230(74.4)$ & 0.129 \\
\hline I feel marijuana has fewer negative health effects than prescription opiate mediations. & $164(83.7)$ & $245(79.8)$ & 0.278 \\
\hline I feel marijuana has fewer negative health effects than prescription medications. & $88(45.1)$ & $104(33.7)$ & $0.01^{\mathrm{a}}$ \\
\hline I feel marijuana can impair one's ability to drive. & $162(83.1)$ & $277(89.6)$ & $0.032^{\mathrm{a}}$ \\
\hline
\end{tabular}

Abbreviations used: MC, medical cannabis; MMJ, medical marijuana.

a Statistically significant, chi-square test.

With respect to indications, this study found that students were most likely to know that cancer (69\%), pain disorders (63.1\%), and epilepsy (62.8\%) were approved indications for MC. This is similar to Caligiuri et al. study in which most pharmacy students at a pharmacy school in Iowa, an illegal MC state, correctly identified cancer (74\%), epilepsy (74\%), and migraines (55\%) as correct indications. ${ }^{10}$ However, results from the current study differ from our previous study conducted in 2011 where the top correct indications were cancer (91\%) and glaucoma (52\%). At the time of the 2011 study survey, only $11 \%$ indicated epilepsy as an indication for cannabis. This sharp knowledge change is likely owing to the recent approval of CBD for seizures and extensive media coverage on cannabis use for seizures. The decline in knowledge for use in cancer (69\% vs. $91 \%$ ) may be due to the previous survey conducted at only 1 institution where MC may have been emphasized in oncology sections of the curriculum compared with this study that surveyed multiple pharmacy schools.

Most pharmacy students in this survey, regardless of their state's legal status, considered cannabis to be safe for medical use (>80\%). The majority of pharmacy students thought that cannabis had fewer adverse health effects than alcohol, tobacco, and opioids. This is consistent with a 2017 survey of family medicine physicians where $85 \%$ of medical residents and $67 \%$ of faculty physicians expressed low concern for cannabis safety (respondents rated items as either low, medium or high concern) and low-medium concern for cannabis's "potential for addiction or its psychoactive problems." ${ }^{23}$ This trend in safety concern was also shown in a 2014 survey of health care professionals practicing in Washington (a MC state), where only $40 \%$ of clinicians viewed MC having significant physical health concerns, and $45 \%$ of clinicians felt MC could result in serious mental health adverse effects. ${ }^{24}$ These studies contrast a 2011 survey of Colorado physicians (MC state) in which greater than $60 \%$ of physicians agreed MC had a significant physical and mental health risk. ${ }^{25}$ Based on our study and other studies, it appears that health care professionals, including pharmacy students, perceptions have followed those of the general public. Felson et al. sought to identify why public opinions have changed dramatically since the 1980s. ${ }^{26}$ The authors found there are multiple factors that may have led the change in public opinion, including a decrease in religious affiliation, a decline in punitiveness, and a shift in media coverage. It is imperative that pharmacists be equipped with the best information possible about the safety and efficacy of MC rather than providing information based on public opinion or media coverage.

Mental health risks and addiction are evolving concerns for MC. According to the National Academies of Science review, there is substantial evidence of a statistical association 
between cannabis use and the development of schizophrenia or other psychoses. ${ }^{5}$ In addition, cannabis has been associated with depressive symptoms, an increase in suicidal thoughts, and worsening of depression in patients with a diagnosis of depression. ${ }^{27-30}$ Nonetheless, less than a quarter of the students in our study listed depression and risk for schizophrenia as an adverse effect. More than $50 \%$ of our respondents agreed that cannabis can be addictive. This is lower than surveys of medical students and physicians, which rated the potential for addiction greater than $80 \% .^{25,31}$ The National Academies of Science review found that there is substantial evidence of a statistical association between increases in cannabis use frequency and the progression to problem cannabis use. ${ }^{5}$ Less than $14 \%$ of students in our survey were comfortable answering questions from patients about drug interactions with MC. Likewise, almost a third of students felt that MC is safe to use with nonprescription and prescription medications. There is the potential for significant drug-drug interactions with THC inhibiting CYP2C9 and 3A4, and smoked cannabis inducing CYP1A2. ${ }^{32}$ In addition, there is the potential for significant pharmacodynamic interactions including additive sedation/cognitive/psychomotor impairment with concomitant central nervous system depressants and cardiac toxicity including hypertension and tachycardia with sympathomimetics. $^{33}$ There is still limited availability of information regarding all the potential drug interactions with $\mathrm{MC}$, thereby suggesting a need for continued research and education on this topic which is of particular importance for pharmacists.

Nearly all students in this survey indicated that they felt instruction on MC was imperative in the pharmacy school curriculum. However, only $15 \%$ indicated they received some formalized instruction on MC. This differs from 2 studies that surveyed educators on pharmacy school's curriculum. These studies both reported that $62 \%$ of pharmacy schools included some MC discussion into the curriculum most commonly regarding indications, adverse effects, and legal status. ${ }^{19,34}$ In both these surveys, response rates were low and did not indicate the depth of instruction (e.g., number of hours taught). The current study, however, surveyed pharmacy students at different stages in the curriculum, and many may not have received MC education at the time of the survey.

This study had limitations. The survey was sent to several schools of pharmacy that did not indicate whether or not the survey would be distributed, so it cannot be determined how many students actually received the survey. When selecting a balanced representation of schools to distribute the survey, the authors did not take in account timing of state legalization or state's recreational status. Students from 7 states that had approved MC completed the survey, with West Virginia last approving MC in 2017. Of the 7 states, Massachusetts was the only state at time of survey distribution that had approved recreational cannabis in 2016, although the first dispensary opened in 2018 during survey distribution. Studies have shown that commercialization of cannabis is correlated with a decreased risk perception. ${ }^{35}$ Consequently, students' perceptions may have been influenced with changing legal status. Furthermore, schools in states where pharmacists have a specified role in MC distribution were solicited (Arkansas, Connecticut, Minnesota, New York, and Pennsylvania); however, no responses were received from students in those states. It is possible that students in these states may have more education in MC and could affect the results of our study. Further studies with students in these states are imperative.

Another limitation of this study is that qualifying conditions or indications for MC differ from state to state. The authors looked at general knowledge across states regarding indications and did not ask or separate out state-specific indications. Students in states where MC is legal may be more familiar with their state-approved uses as opposed to other states' indications. However, the authors chose the most common qualifying conditions to include in the survey.

Whereas 629 students accessed the survey, not all of them completed the entire questionnaire, which may reflect some response bias owing to the topic being surveyed. Those questionnaires with missing data were still included in the analyses but may limit interpretation of the results. Furthermore, it is not possible to verify the number of schools that distributed the survey to students; so neither can the exact response rate be determined nor can the characteristics of nonresponders be examined. Studies have shown poorer response rates with Web-based surveys compared with paper surveys administered through the mail. ${ }^{36}$ There were also some student responses to the demographic questions that appeared incorrect, such as students indicating their university was private when it was actually public, and indicating attending school in a state where the survey was not distributed.

\section{Conclusion}

Although students feel pharmacists should be involved in the dispensing process of MC, this study continues to highlight that pharmacy students are not prepared to recommend, counsel, and interpret drug interactions related to MC. The Accreditation Standards for Pharmacy Education should address this knowledge gap and lack of formal training in pharmacy schools' curriculum. As pharmacists, we are considered the drug experts and will be asked questions regarding efficacy, safety, and drug interactions. It is imperative that pharmacy students and pharmacists be able to engage in an educated discussion with patients and other health care providers about MC and CBD to gain their respect and provide useful education that will be followed.

\section{References}

1. Bridgeman MB, Abazia DT. Medicinal cannabis: history, pharmacology, and implications for the acute care setting. P T. 2017;42(3):180-188.

2. Abazia DT, Bridgeman MB. Reefer madness or real medicine? A plea for incorporating medicinal cannabis in pharmacy curricula. Curr Pharm Teach Learn. 2018;10(9):1165-1167.

3. ProCon.org. 33 legal medical marijuana states and DC: laws, fees, and possession limits. Available at: https://medicalmarijuana.procon.org/ view.resource.php?resourceID=000881. Accessed May 15, 2019.

4. Wilkinson ST, Yarnell S, Radhakrishnan R, Ball SA, D'Souza DC. Marijuana legalization: impact on physicians and public health. Annu Rev Med. 2016;67:453-466.

5. National Academies of Sciences, Engineering, and Medicine. The Health Effects of Cannabis and Cannabinoids: The Current State of Evidence and Recommendations for Research. Washington, DC: National Academies Press; 2017.

6. Epidiolex [Package Insert]. Carlsbad, CA: Greenwich Biosciences Inc; 2018.

7. Cesamet [Package Insert]. Somerset: Meda Pharmaceuticals Inc; 2013.

8. Marinol [Package Insert]. Chicago, IL: AbbVie Inc; 2016.

9. Kelling SE. Exploring accessibility of community pharmacy services. Inov Pharm. 2015;6(3):1-4. 
10. Caligiuri FJ, Ulrich EE, Welter KJ. Pharmacy student knowledge, confidence and attitudes toward medical cannabis and curricular coverage. Am J Pharm Educ. 2018;82(5):6296.

11. Moeller KE, Woods B. Pharmacy students' knowledge and attitudes regarding medical marijuana. Am J Pharm Educ. 2015;79(6):85.

12. Brooks D. Pharmacy's role in medical cannabis. Available at: https:/ www.pharmacytimes.com/contributor/david-book-pharmd/2016/10/ pharmacys-role-in-medical-cannabis. Accessed July 31, 2019.

13. State of Arkansas. House Bill 2190, 91st General Assembly, Regular Session, 2017. Available at: http://www.arkleg.state.ar.us/assembly/2017/2 017R/Bills/HB2190.pdf. Accessed August 1, 2019.

14. Balick R. Pharmacists tread carefully into the world of medical cannabis. Pharm Today. 2018;24(1):28-31.

15. Department of Health, Board of Pharmacy. Marijuana Pharmacy (LAC 46 LIII.Chapter 24). Final rule. Available at: http://www.pharmacy.la.gov/assets/ docs/Cmtes/RegRev/RegProj2016-6_FR.pdf. Accessed July 31, 2019.

16. Hall C. Cannabidiol to be offered at growing number of pharmacies. Available at: https://www.pharmacytimes.com/sap-news/cannabidiol-to-beoffered-at-growing-number-of-pharmacies. Accessed May 16, 2019.

17. American Pharmacists Association. Role of the pharmacist in the care of patients using cannabis. Available at: https://www.pharmacist.com/sites/ default/files/files/Role\%20of\%20the\%20Pharmacist\%20in\%20the\%20Care\% 20of\%20Patients\%20Using\%20Cannabis\%20.pdf. Accessed May 16, 2019.

18. American Society of Health System Pharmacists. ASHP policy positions 1982-2019. Available at: https://www.ashp.org/-/media/assets/policyguidelines/docs/browse-by-document-type-policy-positions-1982-2 017-with-rationales-pdf.ashx. Accessed May 16, 2019.

19. Berlekamp D, Rao PSS, Patton T, Berner J. Surveys of pharmacy students and pharmacy educators regarding medical marijuana. Curr Pharm Teach Learn. 2019;11(7):669-677.

20. Hwang J, Arneson T, St Peter W. Minnesota pharmacists and medical cannabis: a survey of knowledge, concerns, and interest prior to program launch. P T. 2016;41(11):716-722.

21. Szyliowicz D, Hilsenrath P. Medical marijuana knowledge and attitudes: a survey of the California Pharmacists Association. J Prim Care Commun Health. 2019;10, 2150132719831871.

22. Vujcic I, Pavlovic A, Dubljanin E, Maksimovic J, Nikolic A, SipeticGrujicic S. Attitudes toward medical cannabis legalization among Serbian medical students. Subst Use Misuse. 2017;52(9):1225-1231.

23. Ricco J, Danner C, Pereira C, Philbrick A. "The Times They Are A-Changin"': knowledge and perceptions regarding medical cannabis in an academic family medicine department. PRiMER. 2017;1:20.

24. Carlini BH, Garrett SB, Carter GT. Medicinal cannabis: a survey among health care providers in Washington state. Am J Hosp Palliat Care. 2017;34(1):85-91.
25. Kondrad E, Reid A. Colorado family physicians' attitudes toward medical marijuana. J Am Board Fam Med. 2013;26(1):52-60.

26. Felson J, Adamczyk A, Thomas C. How and why have attitudes about cannabis legalization changed so much? Soc Sci Res. 2019;78:12-27.

27. Bahorik AL, Sterling SA, Campbell CI, Weisner C, Ramo D, Satre DD. Medical and non-medical marijuana use in depression: longitudinal associations with suicidal ideation, everyday functioning, and psychiatry service utilization. J Affect Disord. 2018;241:8-14.

28. Chen CY, Wagner FA, Anthony IC. Marijuana use and the risk of Major Depressive Episode. Epidemiological evidence from the United States National comorbidity Survey. Soc Psychiatry Psychiatr Epidemiol. 2002;37(5):199-206.

29. Feingold D, Weiser M, Rehm J, Lev-Ran S. The association between cannabis use and anxiety disorders: results from a population-based representative sample. Eur Neuropsychopharmacol. 2016;26(3): 493-505.

30. Degenhardt L, Hall W, Lynskey M. Exploring the association between cannabis use and depression. Addiction. 2003;98(11):1493-1504.

31. Chan MH, Knoepke CE, Cole ML, McKinnon J, Matlock DD. Colorado medical students' attitudes and beliefs about marijuana. J Gen Intern Med. 2017;32(4):458-463.

32. Rong C, Carmona NE, Lee YL, et al. Drug-drug interactions as a result of co-administering $\Delta^{9}$-THC and CBD with other psychotropic agents. Expert Opin Drug Saf. 2018;17(1):51-54.

33. Lucas CJ, Galettis P, Schneider J. The pharmacokinetics and the pharmacodynamics of cannabinoids. Br J Clin Pharmacol. 2018;84(11): 2477-2482.

34. Smithburger PL, Zemaitis MA, Meyer SM. Evaluation of medical marijuana topics in the PharmD curriculum: a national survey of schools and colleges of pharmacy. Curr Pharm Teach Learn. 2019;11(1):1-9.

35. Schuermeyer J, Salomonsen-Sautel S, Price RK, et al. Temporal trends in marijuana attitudes, availability and use in Colorado compared to nonmedical marijuana states: 2003-11. Drug Alcohol Depend. 2014 $145-155$.

36. Kaplowitz MD, Hadlock TD, Levine R. A comparison of web and mail survey response rates. Public Opin Q. 2004;68(1):94-101.

Karen E. Moeller, PharmD, BCPP, Clinical Professor, Pharmacy Practice, University of Kansas, School of Pharmacy, Lawrence, KS

J. Michael McGuire, PharmD, BCPP, Associate Professor, Pharmacy Practice, Belmont University, School of Pharmacy, Nashville, TN

Brittany L. Melton, PharmD, PhD, Associate Professor, Pharmacy Practice University of Kansas, School of Pharmacy, Lawrence, KS 


\section{Appendix 1}

Q1 - Information on University IRB \& Consent to participate - I wish to continue

$\circ$ Yes (1)

$\circ$ No (2)

Q2 What is your age?

Skip To: End of Survey If What is your age? $<18$

Q3 In what state is your pharmacy school located?

Q4 What is your state or US Territory of permanent residence?

Q5 What is your religious affiliation?

Q6 Do you have a family history of substance abuse?

$\circ$ Yes (1)

$\circ$ No (2)

Q7 Do you personally have a history of substance abuse?

$\circ$ Yes (1)

$\circ$ No (2)

Q8 Is your pharmacy school a public or private institution?

$\circ$ Public (1)

$\circ$ Private (2)

Q9 Is medical marijuana approved for use in the state where you attend pharmacy school?

$\circ$ Yes (1)

$\circ$ No (2)

Q10 Is medical marijuana approved for use in the state that you would identify as your primary state of residence?

$\circ$ Yes (1)

$\circ$ No (2)

Q11 Do you feel that all states should approve the use of medical marijuana?

$\circ$ Yes (1)

$\circ$ No $(2)$

Q12 Do you think marijuana should be legalized for recreational use?

$\circ$ Yes (1)

$\circ$ No (2)

Skip To: Q14 If Do you think marijuana should be legalized for recreational use? $=$ No

Q13 Do you feel that the main reason marijuana should be legalized for recreational use is to help increase tax revenue?

$\circ$ Yes (1)

$\circ$ No (2)

Q14 How many states allow the use of medical marijuana for authorized indications?

- Less than 10 (1)

○ $10-20(2)$

$$
\begin{aligned}
& \circ 21-30(3) \\
& \circ 31-40(4) \\
& \circ 41-50(5)
\end{aligned}
$$

Q15 How many states allow the use of recreational marijuana?

○ Less than 10 (1)

$\circ 10-20(2)$

○ 21-30(3)

○ $31-40(4)$

$\circ 41-50(5)$

Q16 States vary regarding qualified conditions for medical use of marijuana. From the list below, please select which of the following are common uses for medical marijuana.

$\square$ Agitation in Alzheimer's Disease (1)

$\square$ ALS (Lou-Gehrig's Disease) (2)

$\square$ Cancer (3)

$\square$ Crohn's Disease (4)

Hypertension (5)

$\square$ Epilepsy (6)

Glaucoma (7)

$\square$ Hepatitis C (8)

$\square$ Pain Disorders (9)

HIV-AIDS (10)

PTSD (11)

Multiple Sclerosis (12)

Depression (13)

Nausea/Vomiting (14)

Parkinson's Disease (15)

Schizophrenia (16)

Tourette's Syndrome (17)

Sleep Apnea (18)

Cachexia (low body weight) (19)

Q17 For each adverse event or effects listed below, please select which adverse event or effect is associated with marijuana.
$\square$ Water retention (1)
Anxiety (2)
Blurred vision (3)
Muscle aches (4)
Constipation (5)
Depression (6)
Hypoglycemia (7)
Dizziness (8)
Hallucinations (9)
Increased bleeding (10)
Insomnia (11)
Lung cancer (12)
Memory impairment (13)
Nausea (14)
Dependence/ withdrawal (15)
Paranoia (16)
Seizures (17)
Impaired brain development in adolescents (18)
Increased risk for schizophrenia (19)
Worsening asthma (20)
Birth defects (21) 
Q18 Please indicate how strongly you agree or disagree with each of the following statements using the following scale
$1=$ Strongly Disagree
$2=$ Disagree
$3=$ Neutral
$4=$ Agree
$5=$ Strongly Agree

\begin{tabular}{|c|c|c|c|c|c|}
\hline & $\begin{array}{l}\text { Strongly } \\
\text { Disagree (1) }\end{array}$ & Disagree (2) & $\begin{array}{l}\text { Neither agree } \\
\text { nor disagree ( } 3 \text { ) }\end{array}$ & Agree (4) & $\begin{array}{l}\text { Strongly } \\
\text { Agree (5) }\end{array}$ \\
\hline $\begin{array}{l}\text { In my opinion, marijuana should be legalized for } \\
\text { medicinal uses. (1) }\end{array}$ & 0 & 0 & 0 & 0 & 0 \\
\hline $\begin{array}{l}\text { In my opinion, all clinicians with prescribing rights (e.g. } \\
\text { advanced nurse practitioners, physician assistants) } \\
\text { should be able to prescribe medical marijuana. (2) }\end{array}$ & 0 & O & $\bigcirc$ & 0 & 0 \\
\hline $\begin{array}{l}\text { In my opinion, I feel pharmacists should be involved in } \\
\text { the dispensing process for medical marijuana. ( } 3 \text { ) }\end{array}$ & 0 & 0 & 0 & 0 & 0 \\
\hline $\begin{array}{l}\text { I feel that marijuana is safe when used responsibly for } \\
\text { medical use. (4) }\end{array}$ & 0 & O & $\bigcirc$ & $\bigcirc$ & 0 \\
\hline \multicolumn{6}{|l|}{$\begin{array}{l}\text { I feel medical marijuana should be available for use in } \\
\text { children. (5) }\end{array}$} \\
\hline $\begin{array}{l}\text { I feel medical marijuana is safe to use in pregnancy and } \\
\text { lactation. (6) }\end{array}$ & 0 & 0 & 0 & 0 & O \\
\hline $\begin{array}{l}\text { I feel that marijuana can be detrimental to one's health } \\
\text { for medical use. ( } 7 \text { ) }\end{array}$ & 0 & 0 & 0 & 0 & 0 \\
\hline I feel that medical marijuana is often abused. (8) & O & O & O & O & O \\
\hline $\begin{array}{l}\text { I feel that legalizing medical marijuana would cause } \\
\text { crimes rates to increase. (9) }\end{array}$ & O & 0 & 0 & O & 0 \\
\hline $\begin{array}{l}\text { I feel that legalizing medical marijuana would cause } \\
\text { more people to use marijuana in non-medical ways. } \\
\text { (10) }\end{array}$ & O & O & $\bigcirc$ & O & O \\
\hline $\begin{array}{l}\text { I consider myself knowledgeable on the subject of } \\
\text { medical marijuana. (11) }\end{array}$ & 0 & 0 & 0 & 0 & 0 \\
\hline $\begin{array}{l}\text { I understand the difference between delta-9 } \\
\text { tetrahydrocannabinol (THC) and cannabidiol (CBD). } \\
\text { (12) }\end{array}$ & 0 & 0 & 0 & 0 & 0 \\
\hline $\begin{array}{l}\text { I feel comfortable answering questions from my } \\
\text { patients about the efficacy of medical marijuana. (13) }\end{array}$ & 0 & 0 & 0 & 0 & 0 \\
\hline $\begin{array}{l}\text { I feel comfortable answering questions from my } \\
\text { patients about drug interactions with medical } \\
\text { marijuana. (14) }\end{array}$ & 0 & 0 & 0 & 0 & 0 \\
\hline $\begin{array}{l}\text { I feel that medical marijuana is safe to use with } \\
\text { prescription medications. (15) }\end{array}$ & 0 & 0 & 0 & 0 & 0 \\
\hline \multicolumn{6}{|l|}{$\begin{array}{l}\text { I feel that medical marijuana is safe to use with non- } \\
\text { prescription medications. (16) }\end{array}$} \\
\hline $\begin{array}{l}\text { I feel that medical marijuana has been adequately } \\
\text { studied by scientists. (17) }\end{array}$ & O & 0 & 0 & 0 & 0 \\
\hline $\begin{array}{l}\text { I feel that the majority of people who support the } \\
\text { legalization of medical marijuana are drug abusers. } \\
\text { (18) }\end{array}$ & 0 & 0 & 0 & $\bigcirc$ & O \\
\hline \multicolumn{6}{|l|}{$\begin{array}{l}\text { If I had to make a decision today about legalization of } \\
\text { medical marijuana, I would be in favor of doctor } \\
\text { prescribed medical marijuana. (19) }\end{array}$} \\
\hline $\begin{array}{l}\text { I feel that our government has adequate resources to } \\
\text { regulate the use of medical marijuana. (20) }\end{array}$ & 0 & 0 & 0 & $\bigcirc$ & 0 \\
\hline $\begin{array}{l}\text { In my opinion, marijuana should be legalized for the } \\
\text { general population. ( } 21)\end{array}$ & 0 & 0 & 0 & 0 & 0 \\
\hline I feel that marijuana is a gateway drug. (22) & O & & O & $\bigcirc$ & O \\
\hline $\begin{array}{l}\text { I feel that marijuana is safe when used responsibly for } \\
\text { recreational use. (23) }\end{array}$ & 0 & 0 & 0 & 0 & O \\
\hline $\begin{array}{l}\text { I feel that recreational use of marijuana can be } \\
\text { detrimental to one's health. (24) }\end{array}$ & 0 & O & 0 & 0 & 0 \\
\hline $\begin{array}{l}\text { I feel that legalizing marijuana for any use would cause } \\
\text { crime rates to increase. (25) }\end{array}$ & 0 & 0 & 0 & 0 & 0 \\
\hline $\begin{array}{l}\text { I feel marijuana has fewer negative health effects than } \\
\text { alcohol. (26) }\end{array}$ & O & O & O & O & O \\
\hline I feel users can become addicted to marijuana. (27) & O & O & O & O & O \\
\hline I feel marijuana has fewer negative health effects than & $\bigcirc$ & O & $\bigcirc$ & $\bigcirc$ & O \\
\hline
\end{tabular}




\begin{tabular}{|c|c|c|c|c|c|}
\hline & $\begin{array}{l}\text { Strongly } \\
\text { Disagree (1) }\end{array}$ & Disagree (2) & $\begin{array}{l}\text { Neither agree } \\
\text { nor disagree ( } 3 \text { ) }\end{array}$ & Agree (4) & $\begin{array}{l}\text { Strongly } \\
\text { Agree (5) }\end{array}$ \\
\hline $\begin{array}{l}\text { I feel marijuana has fewer negative health effects than } \\
\text { prescription opiate mediations. (29) }\end{array}$ & $\mathrm{O}$ & $\mathrm{O}$ & $\mathrm{O}$ & $\mathrm{O}$ & $\mathrm{O}$ \\
\hline $\begin{array}{l}\text { I feel marijuana has fewer negative health effects than } \\
\text { prescription medications. (30) }\end{array}$ & O & O & O & O & O \\
\hline I feel marijuana can impair one's ability to drive. (31) & 0 & 0 & 0 & 0 & 0 \\
\hline
\end{tabular}

Q19 Have you ever used any form of marijuana (medical or non-medical)?

$\circ$ Yes (1)

$\circ$ No $(2)$

Q20 Have you known anyone to use marijuana for a medical condition?

$\circ$ Yes (1)

$\circ$ No $(2)$

Q21 Does your school of pharmacy include in-depth discussion of medical marijuana in the core curriculum like other drug classes that you are taught?

$\circ$ Yes (1)

$\circ$ No (2)

Q22 Do you feel that professors should include information about medical marijuana in your classes?

$\circ$ Yes (1)

$\circ$ No $(2)$
Q23 Please select the gender you identify with:

$\circ$ Male (1)

- Female (2)

Q24 What is your year in pharmacy school?

$\circ \mathrm{P} 1(1)$

$\circ \mathrm{P} 2(2)$

$\circ \mathrm{P} 3(3)$

$\circ$ P4 (4)

Q25 During your education/training, have you received any specific education about medical marijuana?

$\circ$ Yes $(1)$

$\circ$ No (2)

Skip To: Q26 If During your education/training, have you received any specific education about medical marijuana? $=$ Yes

Q26 Please briefly describe where you learned about medical marijuana:

Q27 Thank you for your participation 